\title{
Therapeutic strategies for brachial plexus injury
}

Hong Huang, Shuangqin Chen, Lin Wu, Yihui Li, Shiying Dou, Qianlan Chen, Zijian Xiao, Heng Wu, Shuangxi Chen

The First Affiliated Hospital, Hengyang Medical School, University of South China, Hengyang, Hunan Province, China

\begin{abstract}
Brachial plexus avulsion (BPA), a severe acute peripheral nerve injury in adults, results in total loss of the motor function in the upper limb. Although immediate re-implantation surgery is widely performed to repair this lesion, the motor function cannot be fully restored. The main cause is that the growth velocity of axon is extremely slow in order to re-innervate the target muscles before atrophy develops. Therefore, the survival of spinal motoneurons (MNs) is considered to be a prerequisite for the recovery of motor function. The introduction of survival-proactive agents with anti-oxidative stress and anti-inflammation properties has emerged as a new approach to the motor function recovery following BPA. In the current review, we summarized the treatments of BPA in both mouse and rat models following re-implantation surgery. Furthermore, the pain treatment options following BPA were discussed.
\end{abstract}

Key words: brachial plexus avulsion (BPA), motoneurons (MNs), pain.

\section{Introduction}

The number of patients suffering from brachial plexus injury (BPI) has been increasing steadily, mostly due to motorbike accidents $[23,30,69]$. Despite neurosurgical repair strategies to restore anatomical continuity between the injured motor axons and the distal nerves, function recovery of the distal musculature is often disappointing [50]. Functional loss is caused by the degeneration of nerve fibres, deficits of synapses and the nerve fibre growth inhibitory effect of glial scarring [10]. Significant motoneuron (MN) loss is reported following root avulsion lesions in adults $[52,92,102]$ and most of the affected MNs ultimately die [39], causing the paralysis of the target muscle groups, as the brachial plexus is the unique nerve reserve to the upper limb. Very little axon regeneration occurred in the spinal cord after acute or chronic injury, due to the stimulation of inhibitory molecules at the injury sites and the low intrinsic capacity for axon growth in neurons in the adult central nervous system (CNS). Multiple treatments have been performed on animal models to investigate the recovery of motor function following brachial plexus root avulsion (BPRA). Re-implantation of avulsed ventral roots temporarily delays $M N$ degeneration and allows staggered regeneration of motor axons over the implantation site into the nerve root $[26,73]$. However, in patients with BPI, axons need to regenerate over distances of up to $80 \mathrm{~cm}$ before reaching their distal target muscles in the lower arm and hand. With an average axonal outgrowth velocity of 1-2 $\mathrm{mm} /$ day, axon regeneration is a protracted process, which requires several months, or even years [24]. To bridge this distance, an extended 
period of regeneration is required, resulting in limited distal regeneration and suboptimal recovery of voluntary function $[28,84]$. Re-implantation surgery, a widely performed approach, cannot entirely repair the motor function due to the slow velocity of axonal growth for the spinal MNs to re-innervate the target sites prior to the development of muscle atrophy $[8,9]$. The survival of MNs is necessary for the functional recovery. As a consequence, early and effective protection of neurons is necessary for lengthening the time window of the treatment and promoting the survival of lesioned MNs [65].

Maintaining the survival of affected MNs is extremely essential for axonal regeneration [40]. Eggers et al. discussed the clinical features and intervention strategies, including acute and delayed implantation, cell implantation, macromolecular intervention, neurotrophic factors and interference with neurite outgrowth inhibitors, presenting a general description of neurotrophic factor treatment and cell-based pharmacological approaches that have been applied in combination with surgical re-implantation [27]. Herein we reviewed the underlying mechanisms associated with oxidative stress and inflammation, and the genes with axonal growth and regeneration, brain changes and other treatments of BPA aimed at promoting MN survival and alleviating pain.

\section{Inflammation and oxidative stress}

Spinal root avulsion causes a multitude of pathophysiological events, including modified expression of genes and proteins associated with inflammation, oxidative stress, and apoptosis, which collectively cause substantial neuronal death [82]. After a primary mechanical injury, the secondary cascade produces reactive oxygen species (ROS) that cause cell damage and apoptosis [49]. Inflammatory cells and microglia accumulate at the injury site and cause neuronal death, aggravating oxidative damage and triggering inflammatory responses [58].

An experimental model of spinal root avulsion simulates the characteristics of human BPA injury [75]. In adult rodent models, ventral root avulsion injury triggers the excessive generation of reactive nitrogen species (RNS), including $\mathrm{NO}$, and $\mathrm{ONOO}^{-}$ [81,91], and ROS as well as $\mathrm{O}_{2}^{\cdot-}, \mathrm{H}_{2} \mathrm{O}_{2}$ and $\cdot \mathrm{OH}$ $[59,64]$. Accumulation of ROS/RNS can overwhelm the body's antioxidant capacity, induce lipid peroxi- dation, protein oxidation and DNA modification [15], and cause oxidative damage at the injury site, leading to progressive MN loss [20]. In addition, another important hallmark of spinal root avulsion is the local neuroinflammatory response in the affected stage, characterized by excessive activated microglia/macrophages and astrocytes infiltrating the lesion sites $[5,105]$, which produce pro-inflammatory cytokines and further inhibit axonal and dendrite regeneration [70], thereby resulting in aggravation of the oxidative insult [37]. Glial activation was observed in mice following BPRA [113]. Effective anti-oxidant and anti-inflammatory treatments can reduce neuronal death and lay the foundation for nerve regeneration.

\section{Molecular changes}

Significant changes of key molecules are associated with neuronal injury, which may be a powerful tool for ameliorating the inflammatory microenvironment and improve nerve regeneration. Activation of c-Jun was suggested to be associated with cell death in neonatal sympathetic neurons $[6,29]$ and hippocampal neurons [77] due to a deprivation of neurotrophic factors. Early up-regulation of the neuronal NOS (nNOS) or inhibition of c-Jun phosphorylation in injured spinal cords may serve as the molecular targeted strategies for preventing the degeneration of MNs in BPRA in the future [24]. Elevated phosphorylated c-Jun level in neonatal spinal MNs after axonal injury has been associated with MN death and regeneration [104].

Previous studies have shown that c-Jun participates directly in regulating the growth-associated protein 43 (GAP-43) [43]. GAP-43 is a small acidic membrane protein associated with successful axonal growth and regeneration in the nervous system $[43,80]$. Both the mRNA and protein levels of GAP-43 elevate after BPI, and the GAP-43 protein is closely related to the axonal regeneration and functional recovery [11]. Yuan et al. reported that GAP-43 increased synchronously with the regeneration of spinal avulsed MNs after BPRA [103]. It was reported that, despite the colocalization of nNOS and GAP-43 in avulsed MNs, GAP-43 plays a more important role for MNs regeneration [101].

Several transcription factors and enzymes have been implicated in BPRA. Estrogen-related receptor $\gamma$ $(E R R \gamma)$ is a vital component in injured MNs and a common marker of $\gamma \mathrm{MNs}$ following BPRA [100]. Endog- 
enous protein kinase $C$ (PKC) and phospholipase- $C \gamma$ $(P L C \gamma)$ were activated in spinal MNs in the unilateral BPRA model. Moreover, suppression of the PLC $\gamma /$ PKC axis was shown to promote avulsion-induced MN death, while stimulation of the PLC $/$ PKC axis remitted avulsion-induced $M N$ death [111]. It was also reported that reducing apurinic/apyrimidinic endonuclease 1 (APE1), a ubiquitously expressed rate-limiting enzyme of DNA damage repairing, renders spinal MNs susceptible to oxidative stress [20]. However, further exploration using human systems is required to define other transcription factors mediating MN survival.

\section{Brain changes}

Several studies suggest that the neurons in the brain undergo fundamental changes after BPA injury. Elevated brain-derived neurotrophic factor (BDNF) and GAP-43 are beneficial for cerebral transhemispheric functional reconstruction after contralateral C7 root transfer following BPA injury [88]. Up to 12 months post operation, faster transhemispheric reorganization is observed after transfer of the contralateral C7 in young recipient nerves with total BPRA [71]. The expression of major histocompatibility complex class I (MHC-I), paired-immunoglobulin-like receptor B (PirB) and cluster of differentiation $3 \zeta(C D 3 \zeta)$ in motor cortex, neurons exhibited an initially decreasing trend both at the mRNA and protein levels on day 7 , which was reversed at 3 months post-injury in BPRA rats [107]. Factors participating in the network of motor cortical remodelling after BPRA display dynamic changes. Major microRNAs (miRNAs/miRs) distributed in the motor cortex, such as miR-101-3p, miR-132, miR-134, miR137-3p and miR-485, play vital roles in regulating neural plasticity and transhemispheric functional reorganization dendrite morphology, spontaneous synaptic responses and transmitter release after cervical spinal nerve root transfer following BPA injury $[61,81,86]$. Functional MRI studies revealed that the levels of proinflammatory cytokines, such as interleukin (IL)-1 $\beta$, IL-6, tumour necrosis factor $\alpha$ (TNF- $\alpha$ ), are important mediators in the neural plasticity and transhemispheric functional reorganization $[33,36,57,98]$. A growing body of evidence offers novel insights into the mechanism through which altered expression of these factors in the brain can improve or impair the MN survival [108].
These results suggest that elucidating the molecular mechanisms underlying the brain changes accompanying by BPA injury may uncover new therapeutic targets for improving motor function recovery.

\section{Interventions for motoneuron survival}

Several combinatorial strategies have been adopted for nerve reimplantation in multiple animal models of root avulsion injury [4,19]. Exogenous glial cell-derived neurotrophic factor (GDNF) combined with foetal lumbar cells transfer resulted in improved MN survival, axonal sprouting and functional recovery after avulsion of spinal roots [74]. Besides, different sources of stem cells are ideal seed cells in peripheral nerve deficit models. Stem cells hold the merits of boosting tissue repair and regeneration by releasing considerate neurotrophic, angiogenic and anti-inflammatory factors which lead to structure remodelling, neovascularization and function restoration $[46,47]$. Interestingly, embryonic spinal cord neurons grafted to the injured distal nerve alleviated MN death, but also promoted axonal regeneration and generation of MNs with locomotive function [109]. Transplantation of human embryonic stem cells overexpressing fibroblast growth factor 2 (FGF-2) exerted a neuroprotective effect following spinal cord ventral root avulsion (VRA), retaining synaptic stability and reducing astroglial reactivity [3]. The injection of embryonic spinal cord-derived cells may be beneficial for preserving the muscle endplates and initiating earlier functional recovery through reducing muscle atrophy after peripheral nerve injury [76]. Contralateral C7 transfer combined with acellular nerve allografts loaded with differentiated adipose stem cells were beneficial for nerve restoration in BPI rats $[60,97]$. Though several studies have reported varied success using stem cell-based therapy to improve BPRA outcomes, more pre-clinical and clinical experiments are needed to testify the constancy of the efficacy before consensus is reached. In general, stem cell-based therapy had increased the proportion of the viable MNs and regained the neurological function, thus indicating the expectant clinical benefits and potential translational value. Further, future explorations are required to lay emphasis on the implications of applying modified stem cells and the optimization of cell implantation protocols. Moreover, axotomized $M N$ regeneration and reinnervation improved by $\sim 2$-fold after timed 


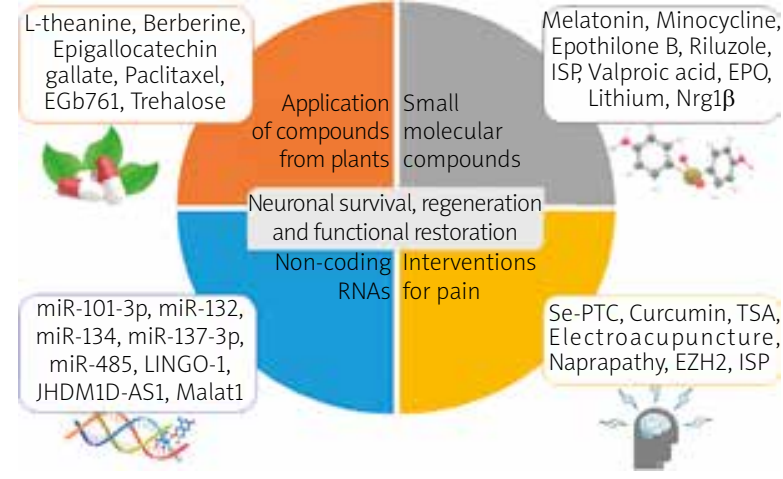

Fig. 1. Ways to promoting nerve survival, regeneration and functional restoration. Representative interventions and selected examples involved in nerve regeneration functional restoration mentioned in this review. ISP - intracellular sigma peptide, EPO - erythropoietin, LINGO-1 - immunoglobulin-like domain-containing NgR-interacting protein 1, Se-PTC - (R)-Se-phenyl thiazolidine-4-carboselenoate, TSA - trichostatin A, EZH2 - enhancer of zeste homolog 2.

GDNF gene delivery in a rat cervical VRA model $[24,25]$. These improvements were associated with a 2-fold increase in regeneration and enhanced reinnervation of the hand musculature. Elucidating the mechanisms involved in the interventions used to promote $M N$ survival may provide new perspectives to recognize biomarkers or identify novel therapeutic targets for enhancing neuronal regeneration in spinal root avulsion injury (Fig. 1).

\section{Application of compounds from plants}

Treatment with plant-derived compounds may exert neuroprotective effects through enhancing nerve regeneration and functional restoration via suppressing neurological oxidative response, inflammation and apoptosis [66]. Tea-derived L-theanine combined with NEP1-40, a competitive antagonist of Nogo receptor (NgR), significantly promoted neuron regeneration after BPRA, and the possible mechanisms included alleviation of oxidative damage and inflammatory responses at the injury sites and antagonism of myelin inhibition [42]. Berberine treatment can upregulate the $\mathrm{L} 1$ expression and axonal remyelination [12], markedly alleviated the avulsion-induced neuroinflammation via down- regulating microglial and astroglial response, while increasing the expression of the antioxidative enzyme superoxide dismutase (SOD), and activating the PI3K/Akt pathway [110]. Intrathecal infusion of paclitaxel, a diterpene alkaloid, represses the expression of neuronal nitric oxide synthase (nNOS) and maintains mitochondrial function in addition to improving MN survival in the ventral horn after spinal root avulsion injury [79]. EGb761, which is a Ginkgo biloba extract containing crucial bioactive constituents, displays neurotherapeutic effects against neuronal apoptotic death and oxidative stress $[2,17,63,90,106]$. Its therapeutic effects partly rely on inhibiting the expression of inducible nitric oxide synthase (iNOS) and nitric oxide (NO) production in a dose-dependent manner [7,51]. Epigallocatechin gallate (EGCG), an active polyphenol isolated from green tea, enhances survival and functional restoration of MNs after BPRA by regulating FIG4 [83]. Trehalose protects MNs in rats by enhancing autophagy and inhibiting apoptosis [53]. Artemisinin (ART), a famous antimalarial medicine, can facilitate the survival of MNs and axonal remyelination to promote the motor function recovery via inhibiting oxidative stress [14]. The aforementioned findings indicate that the application of plant-derived compounds may be a new treatment approach to neuronal damage, and efforts must be made to optimize the utilization of active plants components.

\section{Small molecular compounds}

As the application of small molecular compounds has been associated with gene regulation, elucidating the central factors that affect the occurrence and pathophysiological events in BPRA may be of value. Small molecular compound therapy is likely to be a promising way to improve the outcome of BPRA. Combined injection of melatonin and chondroitin sulfate $A B C$ (ChABC), boosted axonal regeneration via decreasing inflammation, oxidative damage and glial scar formation after BPRA [41]. Minocycline, both intraperitoneally and intrathecally improved MN survival by decreasing microglial proliferation following avulsion of nerve roots [18]. Administration of epothilone $B$, a microtubule-stabilizing drug, facilitated motor functional recovery after spinal root avulsion causing peripheral nerve injury [55]. In delayed spinal cord-brachial plexus reconnection after C7 ventral root avulsion, injured MNs were res- 
cued by riluzole treatment [38]. System delivery of the intracellular sigma peptide (ISP) enhanced the number of axons by targeting the neuronal proteoglycan receptor protein tyrosine phosphatase $\sigma$ $(\mathrm{PTP \sigma})$ in a ventral root avulsion rat model [54]. c-Jun inhibition together with $\mathrm{Bcl}-2$ overexpression promoted regeneration and functional restoration of MNs, whereas valproic acid reduced $M N$ death induced by BPRA [89]. Erythropoietin (EPO) reduced the apoptosis of neurons led by BPRA via inhibiting JNK phosphorylation, c-Jun expression and PARP cleavage [56]. Lithium treatment following spinal root avulsion and reimplantation accelerated motor axon regeneration and remyelination, ameliorated denervated muscle atrophy and promoted earlier motor functional recovery in rats [32,35]. $\mathrm{Nrg} 1 \beta$ improved the functional recovery of elbow flexion, promoted the survival of MNs, enhanced the re-innervation of biceps brachii and decreased muscle atrophy, providing a promising therapeutic approach to root avulsion [13]. Local administration of riluzole may also rescue injured MNs via promoting neuroprotection and increasing nerve regeneration [31].

\section{Non-coding RNAs}

Non-coding RNAs (ncRNAs), such as miRNAs and long non-coding RNAs (IncRNAs), act as post-transcriptional regulators to decrease their downstream target protein expression. Differential expression of the specific ncRNAs at different time points is important after unilateral BPRA. The alterations of associated mRNAs participate in inflammation and regulate the calcium-signalling pathway in the early phase of BPRA and MN death [99]. Tang et al. demonstrated that root avulsion resulted in up-regulation of miR-137-3p, which target calcium-activated neutral protease-2 (calpain-2) and further reduced $\mathrm{nNOS}$ expression in spinal MNs, exhibiting a protective effect against $M N$ death [81]. Ding et al. reported that knockdown of leucine-rich repeat and immunoglobulin-like domain-containing NgR-interacting protein 1 (LINGO-1) by short hairpin (sh)RNA could promote axonal outgrowth and myelination, rehabilitate motor nerve endings, accelerate muscle reinnervation, enhance angiogenesis and promote avulsed forelimb recovery [22]. It was suggested that the increased number of motor endplates and improved angiogenesis was owing to lentiviral vectors-mediated overexpression of hypoxia-inducible factor $1 \alpha$ (HIF-1 $\alpha)$ into reimplanted C6 roots after BPA [85]. Intrathecally applied short interfering (si) RNA to silence the expression of c-Jun manifested that this gene may be responsible for the survival of MNs after root avulsion injury [16]. In addition, targeting miRNAs to indirectly regulate genes involved in inflammation initiated by injury and downstream signalling pathways contributing to $\mathrm{tMN}$ death may be a new route to prevent MN degeneration [82]. The IncRNA JHDM1D-AS1 was shown to exert antiinflammatory and neuroprotective effects via regulating the miR-101-3p/dual-specificity phosphatase 1 (DUSP1) axis in rats following BPRA [61]. Consequently, targeting the differentially expressed IncRNAs and miRNAs induced by BPA injury may uncover novel diagnostic and therapeutic options.

\section{Interventions for pain}

Neurogenic pain is a common and refractory complication after BPA injury [94]. The C-C motif chemokine ligand 2 (CCL2)-/C-C motif chemokine receptor 2 (CCR2) axis can enhance NMDA receptor signalling to aggravate neuropathic pain induced by BPRA [93]. In addition to motor and sensory deficits, pain can be equally debilitating. The main characteristics of BPA pain are its rapid onset (an effect which occurs immediately after the trauma) and the development of long-lasting neuropathy, which may be observed at sites distant from the lesion [62,72]. The neuropathic pain may lead to mechanical allodynia and cold allodynia. Approximately $80 \%$ of patients with BPA are left with long-term neuropathic pain [1]. Spinal astrocytes and microglia were shown to be quickly activated after BPA injury in a neuropathic pain rat model, which may partly explain the mechanism as well as indicate potential treatment options [44]. The antinociceptive organic selenium compound, (R)-Se-phenyl thiazolidine-4-carboselenoate (Se-PTC), displayed superior mechanical and thermal anti-hyperalgesic effects via adjusting cannabinoid receptors $C B 1$ and $C B 2$ in a mouse model of BPA-induced neuropathic pain [21]. Cerebral ${ }^{18} \mathrm{~F}$-FDG metabolism alterations were also observed in a neuropathic pain model following BPA [78]. Treatment of pain post-BPI has been attempted using high-frequency spinal cord stimulation [34]. Administration of trichostatin A (TSA), a histone deacetylase inhibitor, was also shown to alleviate neuropathic pain through reducing neuroinflamma- 
tion, AKT phosphorylation and mTOR signalling in a rat BPA model [112]. Enhancer of zeste homolog 2 $(\mathrm{EZH} 2)$ was shown to modulate neuroinflammation and neuropathic pain via a novel mTOR-mediated autophagy signalling pathway [68]. However, the majority of the traditional treatments have proven to be ineffective for neuropathic pain relief after BPA injury. Accumulating evidence indicates that miRNAs and proteins implicated in nerve development and pathophysiology also play a critical role in BPA-induced neuropathic pain, which may be a potential method for pain relief $[87,112]$. Meng et al. demonstrated that the IncRNA Malat1 ameliorated neuropathic pain by decreasing neuronal excitability via regulation of calcium flux in the spinal cord [67]. The polyphenol curcumin may also alleviate BPA-induced pain by suppressing the levels of proinflammatory cytokines and neuropathic-associated proteins, and deactivating astrocytes [96]. Electroacupuncture and naprapathy have also been used to attenuate neuropathic pain following BPRA $[45,48,95]$.

\section{Conclusions}

BPRA treatment demands various well-planned reconstructive procedures, including physiotherapy, surgery and medications, in addition to management of the intractable neuropathic pain. More clinical experiments are required to evaluate the safety, efficacy and adverse consequences of cell transfer. Other alternative treatments targeting the identified ncRNAs and related signalling pathways may hold promise as therapeutic methods for partial recovery of limb function.

\section{Acknowledgments}

This work was supported by the Hunan Provincial Natural Science Foundation of China (grants nos. 2021JJ70114, 2021JJ30624, 2021JJ30625), Scientific Research Project of Hunan Health Committee (grants nos. 20201911, 20201963), the grants from the Natural Science Foundation of Hunan Province (No. 2019JJ50555), and the Open Project Program of Guangxi Key Laboratory of Centre of Diabetic Systems Medicine, Guilin Medical University (GKLCDSM-20200101-03).

\section{Disclosure}

The authors report no conflict of interest.

\section{References}

1. Abdel-Aziz S, Ghaleb AH. Cervical spinal cord stimulation for the management of pain from brachial plexus avulsion. Pain Med 2014; 15: 712-714.

2. Ahlemeyer B, Krieglstein J. Pharmacological studies supporting the therapeutic use of Ginkgo biloba extract for Alzheimer's disease. Pharmacopsychiatry 2003; 36 Suppl 1: S8-14.

3. Araujo MR, Kyrylenko S, Spejo AB, Castro MV, Ferreira Junior RS, Barraviera B, Oliveira ALR. Transgenic human embryonic stem cells overexpressing FGF2 stimulate neuroprotection following spinal cord ventral root avulsion. Exp Neurol 2017; 294: 45-57.

4. Barbizan R, Castro MV, Rodrigues AC, Barraviera B, Ferreira RS, Oliveira AL. Motor recovery and synaptic preservation after ventral root avulsion and repair with a fibrin sealant derived from snake venom. PLoS One 2013; 8: e63260.

5. Barbizan R, Oliveira AL. Impact of acute inflammation on spinal motoneuron synaptic plasticity following ventral root avulsion. J Neuroinflammation 2010; 7: 29.

6. Bruckner SR, Tammariello SP, Kuan CY, Flavell RA, Rakic P, Estus S. JNK3 contributes to c-Jun activation and apoptosis but not oxidative stress in nerve growth factor-deprived sympathetic neurons. J Neurochem 2001; 78: 298-303.

7. Calapai G, Crupi A, Firenzuoli F, Marciano MC, Squadrito F, Inferrera G, Parisi A, Rizzo A, Crisafulli C, Fiore A, Caputi AP. Neuroprotective effects of Ginkgo biloba extract in brain ischemia are mediated by inhibition of nitric oxide synthesis. Life Sci 2000; 67: 2673-2683.

8. Carlstedt T. Root repair review: basic science background and clinical outcome. Restor Neurol Neurosci 2008; 26: 225-241.

9. Carlstedt T, Anand P, Htut M, Misra P, Svensson M. Restoration of hand function and so called "breathing arm" after intraspinal repair of C5-T1 brachial plexus avulsion injury. Case report. Neurosurg Focus 2004; 16: E7.

10. Carlstedt T, James N, Risling M. Surgical reconstruction of spinal cord circuit provides functional return in humans. Neural Regen Res 2017; 12: 1960-1963.

11. Chen LJ, Ren YH, Liu L, Zhang XQ, Zhao Y, Wu WT, Li F. Upregulated expression of GAP-43 mRNA and protein in anterior horn motoneurons of the spinal cord after brachial plexus injury. Arch Med Res 2010; 41: 513-518.

12. Chen S, He B, Zhou G, Xu Y, Wu L, Xie Y, Li Y, Huang J, Wu H, Xiao $Z$. Berberine enhances $L 1$ expression and axonal remyelination in rats after brachial plexus root avulsion. Brain Behav 2020; 10: e01792.

13. Chen S, Hou Y, Zhao Z, Luo Y, Lv S, Wang Q, Li J, He L, Zhou L, Wu W. Neuregulin-1 accelerates functional motor recovery by improving motoneuron survival after brachial plexus root avulsion in mice. Neuroscience 2019; 404: 510-518.

14. Chen S, Wu L, He B, Zhou G, Xu Y, Zhu G, Xie J, Yao L, Huang J, $\mathrm{Wu} \mathrm{H}$, Xiao Z. Artemisinin facilitates motor function recovery by enhancing motoneuronal survival and axonal remyelination in rats following brachial plexus root avulsion. ACS Chem Neurosci 2021; 12: 3148-3156.

15. Cheng P, Kuang F, Ju G. Aescin reduces oxidative stress and provides neuroprotection in experimental traumatic spinal cord injury. Free Radic Biol Med 2016; 99: 405-417. 
16. Cheng X, Fu R, Gao M, Liu S, Li YQ, Song FH, Bruce IC, Zhou LH, Wu W. Intrathecal application of short interfering RNA knocks down c-jun expression and augments spinal motoneuron death after root avulsion in adult rats. Neuroscience 2013; 241: 268-279.

17. Cheng X, Liu FL, Zhang J, Wang LL, Li FL, Liu S, Zhou LH. EGb761 protects motoneurons against avulsion-induced oxidative stress in rats. J Brachial Plex Peripher Nerve Inj 2010; 5: 12.

18. Chin TY, Kiat SS, Faizul HG, Wu W, Abdullah JM. The effects of minocycline on spinal root avulsion injury in rat model. Malays I Med Sci 2017; 24: 31-39.

19. Chu TH, Du Y, Wu W. Motor nerve graft is better than sensory nerve graft for survival and regeneration of motoneurons after spinal root avulsion in adult rats. Exp Neurol 2008; 212: 562565.

20. Chu TH, Guo A, Wu W. Down-regulation of apurinic/apyrimidinic endonuclease 1 (APE1) in spinal motor neurones under oxidative stress. Neuropathol Appl Neurobiol 2014; 40: 435-451.

21. Del Fabbro L, Borges Filho C, Cattelan Souza L, Savegnago L, Alves D, Henrique Schneider P, de Salles HD, Jesse CR. Effects of Se-phenyl thiazolidine-4-carboselenoate on mechanical and thermal hyperalgesia in brachial plexus avulsion in mice: mediation by cannabinoid CB1 and CB2 receptors. Brain Res 2012; 1475: 31-36.

22. Ding L, Zhu Z, Wang Y, Zeng L, Wang T, Luo J, Zou TB, Li R, Sun X, Zhou G, Liu X, Wu HF. LINGO-1 shRNA loaded by pluronic F-127 promotes functional recovery after ventral root avulsion. Tis sue Eng Part A 2019; 25: 1381-1395.

23. Dorsi MJ, Hsu W, Belzberg AJ. Epidemiology of brachial plexus injury in the pediatric multitrauma population in the United States. J Neurosurg Pediatr 2010; 5: 573-577.

24. Eggers R, de Winter F, Arkenaar C, Tannemaat MR, Verhaagen J. Enhanced regeneration and reinnervation following timed GDNF gene therapy in a cervical ventral root avulsion. Exp Neurol 2019; 321: 113037.

25. Eggers R, de Winter F, Hoyng SA, Hoeben RC, Malessy MJA, Tannemaat MR, Verhaagen J. Timed GDNF gene therapy using an immune-evasive gene switch promotes long distance axon regeneration. Brain 2019; 142: 295-311.

26. Eggers R, Hendriks WT, Tannemaat MR, van Heerikhuize JJ, Pool CW, Carlstedt TP, Zaldumbide A, Hoeben RC, Boer GJ, Verhaagen J. Neuroregenerative effects of lentiviral vector-mediated GDNF expression in reimplanted ventral roots. Mol Cell Neurosci 2008; 39: 105-117.

27. Eggers R, Tannemaat MR, De Winter F, Malessy MJ, Verhaagen J. Clinical and neurobiological advances in promoting regeneration of the ventral root avulsion lesion. Eur J Neurosci 2016; 43: 318-335.

28. Eggers R, Tannemaat MR, Ehlert EM, Verhaagen J. A spatio-temporal analysis of motoneuron survival, axonal regeneration and neurotrophic factor expression after lumbar ventral root avulsion and implantation. Exp Neurol 2010; 223: 207-220.

29. Eilers A, Whitfield J, Shah B, Spadoni C, Desmond H, Ham J. Direct inhibition of c-Jun $\mathrm{N}$-terminal kinase in sympathetic neurones prevents c-jun promoter activation and NGF withdrawal-induced death. J Neurochem 2001; 76: 1439-1454.
30. Faglioni W, Jr., Siqueira MG, Martins RS, Heise CO, Foroni L. The epidemiology of adult traumatic brachial plexus lesions in a large metropolis. Acta Neurochir (Wien) 2014; 156: 1025-1028.

31. Fang J, Li L, Zhai H, Qin B, Quan D, Shi E, Zhu M, Yang J, Liu X, $\mathrm{Gu}$ L. Local riluzole release from a thermosensitive hydrogel rescues injured motoneurons through nerve root stumps in a brachial plexus injury rat model. Neurochem Res 2020; 45: 2800-2813.

32. Fang $X Y$, Zhang WM, Zhang CF, Wong WM, Li W, Wu W, Lin JH. Lithium accelerates functional motor recovery by improving remyelination of regenerating axons following ventral root avulsion and reimplantation. Neuroscience 2016; 329: 213-225.

33. Feigerlova E, Battaglia-Hsu SF. Cytokines in endocrine dysfunction of plasma cell disorders. Mediators Inflamm 2017; 2017: 7586174.

34. Floridia D, Cerra F, Guzzo G, Marino S, Muscara N, Corallo F, Bramanti A, Chillura A, Naro A. Treatment of pain post-brachial plexus injury using high-frequency spinal cord stimulation. J Pain Res 2018; 11: 2997-3002.

35. Fu R, Tang Y, Ling ZM, Li YQ, Cheng X, Song FH, Zhou LH, Wu W. Lithium enhances survival and regrowth of spinal motoneurons after ventral root avulsion. BMC Neurosci 2014; 15: 84.

36. Gao KM, Hu JJ, Lao J, Zhao X. Evaluation of nerve transfer options for treating total brachial plexus avulsion injury: A retrospective study of 73 participants. Neural Regen Res 2018; 13: 470-476.

37. Giulian D. Reactive glia as rivals in regulating neuronal survival. Glia 1993; 7: 102-110.

38. Gloviczki B, Torok DG, Marton G, Gal L, Bodzay T, Pinter S, Nogradi A. Delayed spinal cord-brachial plexus reconnection after C7 ventral root avulsion: the effect of reinnervating motoneurons rescued by riluzole treatment. J Neurotrauma 2017; 34: 2364-2374.

39. Gu HY, Chai H, Zhang JY, Yao ZB, Zhou LH, Wong WM, Bruce I, Wu WT. Survival, regeneration and functional recovery of motoneurons in adult rats by reimplantation of ventral root following spinal root avulsion. Eur I Neurosci 2004; 19: 2123-2131.

40. Guo J, Zhao X, Lao J, Gao K. Why it is necessary to use the entire root rather than partial root when doing contralateral $C 7$ nerve transfer: cortical plasticity also matters besides the amount of nerve fibers. Neural Plast 2021; 2021: 8819380.

41. Guo WL, Qi ZP, Yu L, Sun TW, Qu WR, Liu QQ, Zhu Z, Li R. Melatonin combined with chondroitin sulfate $A B C$ promotes nerve regeneration after root-avulsion brachial plexus injury. Neural Regen Res 2019; 14: 328-338.

42. Guo WL, Qu WR, Zeng LN, Qi ZP, Huang C, Zhu Z, Li R. I-Theanine and NEP1-40 promote nerve regeneration and functional recovery after brachial plexus root avulsion. Biochem Biophys Res Commun 2019; 508: 1126-1132.

43. Herdegen T, Skene P, Bahr M. The c-Jun transcription factor--bipotential mediator of neuronal death, survival and regeneration. Trends Neurosci 1997; 20: 227-231.

44. Hou AL, Xu WD. A model of neuropathic pain in brachial plexus avulsion injury and associated spinal glial cell activation. J Pain Res 2018; 11: 3171-3179.

45. Hou AL, Zheng MX, Hua XY, Huo BB, Shen J, Xu JG. Electroacupuncture-related metabolic brain connectivity in neuropathic 
pain due to brachial plexus avulsion injury in rats. Front Neural Circuits 2020; 14: 35

46. Huang H, Liu J, Hao H, Chen D, Zhizhong L, Li M, Song H, Xiang R, Jiang C, Fu X, Han W. Preferred M2 polarization by ASC-based hydrogel accelerated angiogenesis and myogenesis in volumetric muscle loss rats. Stem Cells Int 2017; 2017: 2896874.

47. Huang H, Liu J, Hao H, Tong C, Ti D, Liu H, Song H, Jiang C, Fu X, Han W. G-CSF Administration after the intraosseous infusion of hypertonic hydroxyethyl starches accelerating wound healing combined with hemorrhagic shock. Biomed Res Int 2016; 2016: 5317630

48. Huo BB, Zheng MX, Hua XY, Shen J, Wu JJ, Xu JG. Brain metabolism in rats with neuropathic pain induced by brachial plexus avulsion injury and treated via electroacupuncture. J Pain Res 2020; 13: 585-595.

49. Jaafaru MS, Nordin N, Shaari K, Rosli R, Abdull Razis AF. Isothiocyanate from Moringa oleifera seeds mitigates hydrogen peroxide-induced cytotoxicity and preserved morphological features of human neuronal cells. PLoS One 2018; 13: e0196403.

50. Kachramanoglou C, Carlstedt T, Koltzenburg M, Choi D. Longterm outcome of brachial plexus reimplantation after complete brachial plexus avulsion injury. World Neurosurg 2017; 103: 28-36.

51. Kobuchi H, Droy-Lefaix MT, Christen Y, Packer L. Ginkgo biloba extract (EGb 761): inhibitory effect on nitric oxide production in the macrophage cell line RAW 264.7. Biochem Pharmacol 1997; 53: 897-903.

52. Koliatsos VE, Price WL, Pardo CA, Price DL. Ventral root avulsion: an experimental model of death of adult motor neurons. J Comp Neurol 1994; 342: 35-44.

53. Li B, Li P, Weng R, Wu Z, Qin B, Fang J, Wang Y, Qiu S, Yang J, Gu L. Trehalose protects motorneuron after brachial plexus root avulsion by activating autophagy and inhibiting apoptosis mediated by the AMPK signaling pathway. Gene 2021; 768: 145307.

54. Li H, Wong C, Li W, Ruven C, He L, Wu X, Lang BT, Silver J, Wu W. Enhanced regeneration and functional recovery after spinal root avulsion by manipulation of the proteoglycan receptor PTPsigma. Sci Rep 2015; 5: 14923.

55. Li H, Wu W. Microtubule stabilization promoted axonal regeneration and functional recovery after spinal root avulsion. Eur J Neurosci 2017; 46: 1650-1662.

56. Li K, Cao RJ, Zhu XJ, Liu XY, Li LY, Cui SS. Erythropoietin attenuates the apoptosis of adult neurons after brachial plexus root avulsion by downregulating JNK phosphorylation and c-Jun expression and inhibiting c-PARP cleavage. J Mol Neurosci 2015; 56: 917-925.

57. Li QY, Xu HY, Yang HJ. Effect of proinflammatory factors TNF-alpha,IL-1beta, IL-6 on neuropathic pain. Zhongguo Zhong Yao Za Zhi 2017; 42: 3709-3712.

58. Li X, Wang T, Zhang D, Li H, Shen H, Ding X, Chen G. Andrographolide ameliorates intracerebral hemorrhage induced secondary brain injury by inhibiting neuroinflammation induction. Neuropharmacology 2018; 141: 305-315.

59. Liu D, Yang R, Yan X, McAdoo DJ. Hydroxyl radicals generated in vivo kill neurons in the rat spinal cord: electrophysiological, histological, and neurochemical results. J Neurochem 1994; 62: 37-44.

60. Liu L, Zhao X, Silva M, Li S, Xing X, Zheng W. Artemisinin protects motoneurons against axotomy-induced apoptosis through activation of the PKA-Akt signaling pathway and promotes neural stem/progenitor cells differentiation into NeuN(+) neurons. Pharmacol Res 2020; 159: 105049.

61. Liu LP, Zhang J, Pu B, Li WQ, Wang YS. Upregulation of JHDM1D-AS1 alleviates neuroinflammation and neuronal injury via targeting miR-101-3p-DUSP1 in spinal cord after brachial plexus injury. Int Immunopharmacol 2020; 89: 106962.

62. Liu Y, Wang L, Meng C, Zhou Y, Lao J, Zhao X. A new model for the study of neuropathic pain after brachial plexus injury. Injury 2017; 48: 253-261.

63. Luo Y, Smith JV, Paramasivam V, Burdick A, Curry KJ, Buford JP, Khan I, Netzer WJ, Xu H, Butko P. Inhibition of amyloid-beta aggregation and caspase-3 activation by the Ginkgo biloba extract EGb761. Proc Natl Acad Sci U S A 2002; 99: 12197-12202.

64. Martin LJ, Kaiser A, Price AC. Motor neuron degeneration after sciatic nerve avulsion in adult rat evolves with oxidative stress and is apoptosis. J Neurobiol 1999; 40: 185-201.

65. McKay Hart A, Brannstrom T, Wiberg M, Terenghi G. Primary sensory neurons and satellite cells after peripheral axotomy in the adult rat: timecourse of cell death and elimination. Exp Brain Res 2002; 142: 308-318.

66. Meira NA, Rocha LW, da Silva GF, Quintal ZM, Delle Monache F, Cechinel Filho V, Quintao NL. Chrysophyllum cainito leaves are effective against pre-clinical chronic pain models: analysis of crude extract, fraction and isolated compounds in mice. J Ethnopharmacol 2016; 184: 30-41.

67. Meng C, Yang X, Liu Y, Zhou Y, Rui J, Li S, Xu C, Zhuang Y, Lao J, Zhao $X$. Decreased expression of IncRNA Malat1 in rat spinal cord contributes to neuropathic pain by increasing neuron excitability after brachial plexus avulsion. J Pain Res 2019; 12: 1297-1310.

68. Meng XL, Fu P, Wang L, Yang X, Hong G, Zhao X, Lao J. Increased EZH2 levels in anterior cingulate cortex microglia aggravate neuropathic pain by inhibiting autophagy following brachial plexus avulsion in rats. Neurosci Bull 2020; 36: 793-805.

69. Midha R. Epidemiology of brachial plexus injuries in a multitrauma population. Neurosurgery 1997; 40: 1182-1188; discussion 1188-1189.

70. Ohlsson M, Hoang TX, Wu J, Havton LA. Glial reactions in a rodent cauda equina injury and repair model. Exp Brain Res 2006; 170: 52-60.

71. Pan F, Wei HF, Chen L, Gu YD. Different functional reorganization of motor cortex after transfer of the contralateral C7 to different recipient nerves in young rats with total brachial plexus root avulsion. Neurosci Lett 2012; 531: 188-192.

72. Rodrigues-Filho R, Santos AR, Bertelli JA, Calixto JB. Avulsion injury of the rat brachial plexus triggers hyperalgesia and allodynia in the hindpaws: a new model for the study of neuropathic pain. Brain Res 2003; 982: 186-194.

73. Romeo-Guitart D, Fores J, Herrando-Grabulosa M, Valls R, LeivaRodriguez T, Galea E, Gonzalez-Perez F, Navarro X, Petegnief V, Bosch A, Coma M, Mas JM, Casas C. Neuroprotective drug for 
nerve trauma revealed using artificial intelligence. Sci Rep 2018; 8: 1879.

74. Ruven C, Badea SR, Wong WM, Wu W. Combination treatment with exogenous GDNF and fetal spinal cord cells results in better motoneuron survival and functional recovery after avulsion injury with delayed root reimplantation. I Neuropathol Exp Neurol 2018; 77: 325-343.

75. Ruven C, Chan TK, Wu W. Spinal root avulsion: an excellent model for studying motoneuron degeneration and regeneration after severe axonal injury. Neural Regen Res 2014; 9: 117118.

76. Ruven C, Li W, Li H, Wong WM, Wu W. Transplantation of embryonic spinal cord derived cells helps to prevent muscle atrophy after peripheral nerve injury. Int J Mol Sci 2017; 18: 511.

77. Schlingensiepen KH, Schlingensiepen R, Kunst M, Klinger I, Gerdes W, Seifert W, Brysch W. Opposite functions of jun-B and $c$-jun in growth regulation and neuronal differentiation. Dev Genet 1993; 14: 305-312.

78. Shen J, Huo BB, Hua XY, Zheng MX, Lu YC, Wu JJ, Shan CL, Xu JG. Cerebral (18)F-FDG metabolism alteration in a neuropathic pain model following brachial plexus avulsion: A PET/CT study in rats. Brain Res 2019; 1712: 132-138.

79. Sim SK, Tan YC, Tee JH, Yusoff AA, Abdullah JM. Paclitaxel inhibits expression of neuronal nitric oxide synthase and prevents mitochondrial dysfunction in spinal ventral horn in rats after C7 spinal root avulsion. Turk Neurosurg 2015; 25: 617-624.

80. Skene JH, Willard M. Axonally transported proteins associated with axon growth in rabbit central and peripheral nervous systems. J Cell Biol 1981; 89: 96-103.

81. Tang Y, Fu R, Ling ZM, Liu LL, Yu GY, Li W, Fang XY, Zhu Z, Wu WT, Zhou LH. MiR-137-3p rescue motoneuron death by targeting calpain-2. Nitric Oxide 2018; 74: 74-85.

82. Tang Y, Ling ZM, Fu R, Li YQ, Cheng X, Song FH, Luo HX, Zhou LH. Time-specific microRNA changes during spinal motoneuron degeneration in adult rats following unilateral brachial plexus root avulsion: ipsilateral vs. contralateral changes. BMC Neurosci 2014; 15: 92.

83. Tang Y, Wang J, Wan S, Luo L, Qiu Y, Jiang S, Yue G, Tang Y, Tang W. Epigallocatechin gallate enhances the motor neuron survival and functional recovery after brachial plexus root avulsion by regulating FIG4. Folia Neuropathologica 2019; 57: 340-347.

84. Torres-Espin A, Corona-Quintanilla DL, Fores J, Allodi I, Gonzalez F, Udina E, Navarro X. Neuroprotection and axonal regeneration after lumbar ventral root avulsion by re-implantation and mesenchymal stem cells transplant combined therapy. Neurotherapeutics 2013; 10: 354-368.

85. Wang T, Zeng LN, Zhu Z, Wang YH, Ding L, Luo WB, Zhang XM, He ZW, Wu HF. Effect of lentiviral vector-mediated overexpression of hypoxia-inducible factor 1 alpha delivered by pluronic F-127 hydrogel on brachial plexus avulsion in rats. Neural Regen Res 2019; 14: 1069-1078.

86. Wang XH, Li LJ, Sun GX, Wu ZP, Li JF, Gu YD. Expressions of miR132, miR-134, and miR-485 in rat primary motor cortex during transhemispheric functional reorganization after contralateral seventh cervical spinal nerve root transfer following brachial plexus avulsion injuries. Neuroreport 2016; 27: 12-17.
87. Wang Y, Wang S, He JH. Transcriptomic analysis reveals essential microRNAs after peripheral nerve injury. Neural Regen Res 2021; 16: 1865-1870.

88. Wei HF, Zeng BF, Chen YF, Chen L, Gu YD. BDNF and GAP43 contribute to dynamic transhemispheric functional reorganization in rat brain after contralateral C7 root transfer following brachial plexus avulsion injuries. Neurosci Lett 2011; 500: 187-191.

89. Wu D, Li Q, Zhu X, Wu G, Cui S. Valproic acid protection against the brachial plexus root avulsion-induced death of motoneurons in rats. Microsurgery 2013; 33: 551-559.

90. Wu T, Fang X, Xu J, Jiang Y, Cao F, Zhao L. Synergistic effects of ginkgolide $B$ and protocatechuic acid on the treatment of Parkinson's disease. Molecules 2020; 25: 3976.

91. Wu W. Expression of nitric-oxide synthase (NOS) in injured CNS neurons as shown by NADPH diaphorase histochemistry. Exp Neurol 1993; 120: 153-159.

92. Wu W, Li L, Yick LW, Chai H, Xie Y, Yang Y, Prevette DM, Oppenheim RW. GDNF and BDNF alter the expression of neuronal NOS, c-Jun, and p75 and prevent motoneuron death following spinal root avulsion in adult rats. J Neurotrauma 2003; 20 : 603-612.

93. Xian H, Jiang Y, Zhang H, Ma SB, Zhao R, Cong R. CCL2-CCR2 axis potentiates NMDA receptor signaling to aggravate neuropathic pain induced by brachial plexus avulsion. Neuroscience 2020; 425: 29-38.

94. Xian H, Xie R, Luo C, Cong R. Comparison of different in vivo animal models of brachial plexus avulsion and its application in pain study. Neural Plast 2020; 2020: 8875915.

95. Xiao B, Ma A, Li Z, Zhang S, Xu X, Zhou J, Li W, Zhang J, Yao F. Naprapathy attenuates neuropathic pain after brachial plexus injury. Ann Palliat Med 2020; 9: 766-773.

96. Xie W, Kang Z, Jiang C, Liu N. Administration of curcumin alleviates neuropathic pain in a rat model of brachial plexus avulsion. Pharmacology 2019; 103: 324-332.

97. Yang JT, Fang JT, Li L, Chen G, Qin BG, Gu LQ. Contralateral C7 transfer combined with acellular nerve allografts seeded with differentiated adipose stem cells for repairing upper brachial plexus injury in rats. Neural Regen Res 2019; 14: 1932-1940.

98. Yang MJ, Li S, Yang CS, Wang XJ, Chang SM, Sun GX. Dynamic alterations of the levels of tumor necrosis factor-alpha, interleukin-6, and interleukin-1beta in rat primary motor cortex during transhemispheric functional reorganization after contralateral seventh cervical spinal nerve root transfer following brachial plexus avulsion injuries. Neuroreport 2017; 28: 279 284

99. Yu G, Zilundu PLM, Xu X, Li Y, Zhou Y, Zhong K, Fu R, Zhou LH. The temporal pattern of brachial plexus root avulsion-induced IncRNA and mRNA expression prior to the motoneuron loss in the injured spinal cord segments. Neurochem Int 2020; 132: 104611.

100. Yu LM, Dong X, Xue XD, X U S, Zhang X, Xu YL, Wang ZS, Wang Y, Gao H, Liang YX, Yang Y, Wang HS. Melatonin attenuates diabetic cardiomyopathy and reduces myocardial vulnerability to ischemia-reperfusion injury by improving mitochondrial quality control: role of SIRT6. J Pineal Res 2020; e12698.

101. Yuan Q, Hu B, Chu TH, Su H, Zhang W, So KF, Lin Z, Wu W. Co-expression of GAP-43 and nNOS in avulsed motoneurons and 
their potential role for motoneuron regeneration. Nitric Oxide 2010; 23: 258-263.

102. Yuan Q, Hu B, So KF, Wu W. Age-related reexpression of p75 in axotomized motoneurons. Neuroreport 2006; 17: 711-715.

103. Yuan Q, Hu B, Su H, So KF, Lin Z, Wu W. GAP-43 expression correlates with spinal motoneuron regeneration following root avulsion. J Brachial Plex Peripher Nerve Inj 2009; 4: 18.

104. Yuan Q, Su H, Guo J, Wu W, Lin ZX. Induction of phosphorylated c-Jun in neonatal spinal motoneurons after axonal injury is coincident with both motoneuron death and regeneration. J Anat 2014; 224: 575-582.

105. Yuan Q, Xie Y, So KF, Wu W. Inflammatory response associated with axonal injury to spinal motoneurons in newborn rats. Dev Neurosci 2003; 25: 72-78.

106.Zeng GR, Zhou SD, Shao YJ, Zhang MH, Dong LM, Lv JW, Zhang HX, Tang YH, Jiang DJ, Liu XM. Effect of Ginkgo biloba extract-761 on motor functions in permanent middle cerebral artery occlusion rats. Phytomedicine 2018; 48: 94-103.

107. Zhang J, Chen L, Gu YD. Changes in expressions of major histocompatibility complex class I, paired-immunoglobulin-like receptor B, and cluster of differentiation 3zeta in motor cortical representations of the brachial plexus after avulsion in rats. World Neurosurg 2017; 106: 211-218.

108. Zhang J, Chen L, Gu YD. Influence of contralateral homologous cortices on motor cortical reorganization after brachial plexus injuries in rats. Neurosci Lett 2015; 606: 18-23.

109.Zhang W, Fang X, Zhang C, Li W, Wong WM, Xu Y, Wu W, Lin J. Transplantation of embryonic spinal cord neurons to the injured distal nerve promotes axonal regeneration after delayed nerve repair. Eur I Neurosci 2017; 45: 750-762.

110. Zhang X, Liu XD, Xian YF, Zhang F, Huang PY, Tang Y, Yuan QJ, Lin ZX. Berberine enhances survival and axonal regeneration of motoneurons following spinal root avulsion and re-implantation in rats. Free Radic Biol Med 2019; 143: 454-470.

111. Zhao XC, Wang LL, Wang YQ, Song FH, Li YQ, Fu R, Zheng WH, Wu W, Zhou LH. Activation of phospholipase-Cgamma and protein kinase $C$ signal pathways helps the survival of spinal motoneurons injured by root avulsion. J Neurochem 2012; 121: 362-372.

112. Zhao Y, Wu T. Histone deacetylase inhibition inhibits brachial plexus avulsion-induced neuropathic pain. Muscle Nerve 2018; 58: 434-440.

113. Zhong K, Li Y, Tang Y, Yu G, Zilundu PLM, Wang Y, Zhou Y, Xu X, $\mathrm{Fu}$ R, Zhou L. Cytokine profile and glial activation following brachial plexus roots avulsion injury in mice. J Neuroimmunol 2021; 353: 577517 